\title{
The Evolution of Knowledge during the Cambrian Explosion
}

\author{
Walter Veit ${ }^{1}$
}

Abstract:

Phillips et al. make a compelling case for a reversal in the current paradigm in 'Other Minds' research by considering the representation of other people's knowledge more basic than the attribution of belief. Unfortunately, they only discuss primates. In this commentary, I argue that the representation of others' knowledge is an evolutionary ancient trait, first appearing during the Cambrian explosion.

Please cite as: Veit, W. (forthcoming). The Evolution of Knowledge during the Cambrian Explosion. Behavioral and Brain Sciences.

In their target article "Knowledge before Belief' by Phillips et al. (2020), we are presented with a radical reversal of the current paradigm in 'Other Minds' research. Breaking with a long tradition that sought to understand the minds of other humans (and animals) by focusing on the attribution of beliefs, the authors argue that decades of empirical research in the cognitive sciences have undermined or at least begun to call into question the assumption that the attribution of knowledge rests on a more basic or fundamental capacity to attribute beliefs. For historical, methodological, and philosophical reasons, however, other minds research has long been held back from even considering this option in the conceptual space.

One way to formulate the underlying problem is to ask which way of representing the minds of others came first - the representation of knowledge or of beliefs? By first here I mean something stronger than just during the course of human development, i.e. first in the sense of being evolutionarily more ancient. Unfortunately, Phillips et al. have little to say about the evolutionary history of these traits and, perhaps more worryingly, seem to conflate evolution and development, discussing both under the banner of whether the representation of other people's knowledge occurs first or later in human infancy. But the order of appearance of these traits in human development may not be the same as in evolutionary history. Ontogeny does not have to track phylogeny. By not paying heed to this fallacy, however, evolutionarily problematic conclusions straightforwardly follow. If one assumes, for instance, that representation of beliefs come developmentally prior in humans, one will only grant representation of others' knowledge to those animals that are also able to also represent the others' beliefs. But as Phillips et al. themselves recognize, the latter ability may turn out to be unique to humans. This would then lead to the phylogenetically untenable conclusion that humans are the only creatures on this planet able to represent the mental states of others.

Naturally, there are multiple ways out of this dilemma - and the most attractive one will certainly be to outright reject the notion that the ability to represent others' beliefs comes first. Phillips et al. accumulate supporting evidence from nonhuman primate species to make the case that the human ability to represent beliefs is phylogenetically recent (Marticorena et al., 2011; Martin \& Santos, 2014, 2016), but I think that they could have dived much deeper into our evolutionary history to support their case.

\footnotetext{
1wrwveit@gmail.com; The University of Sydney; https://walterveit.com/
} 
Approximately 541 million years, in fact, for this is the beginning of the Cambrian explosion when most animal body plans first appeared (Maloof et al. 2010). The ability to track other's knowledge is, I shall argue, an evolutionary ancient trait appearing roughly at the beginning of the Cambrian. What is notable in the early Cambrian is an increase in body size and the emergence of various sensory modalities to track one's environment. But more sophisticated ways of sensing one's surrounding naturally led ways of sensing others - to react. This emergence of a richer kind of agency gave rise to arms races between predators and prey (Bengtson 2002) and the evolution of centralized nervous systems (Wray 2015) to coordinate action and perception. It is during this special period that some philosophers and scientists locate the origins of subjectivity and subjective experience (Godfrey-Smith 2017; Ginsburg \& Jablonka 2019). In research on animal consciousness, there is a temptation to look for human indicators - signs of conscious experience that are perhaps unique to human life. But such approaches give rise to views that draw firm boundaries between us and other animals (Veit \& Huebner 2020), a problem that is similarly present in research on the origins of other minds' representation. To switch from the rich intentional belief-attribution to the perhaps computationally simpler knowledge-attribution may reveal a picture in which the latter is evolutionarily truly ancient. Daniel Dennett's intentional stance program has long emphasized that the ability to attribute beliefs should not be conceived as the sudden emergence of a new sophisticated faculty in human, but one that is similarly present in other animals (Dennett 1987; Veit et al. 2020). Now, we may have to recognize that it should have been the attribution of knowledge to others that deserves our attention here.

An important observation made by Godfrey-Smith (2016) is that there is a transition somewhere in the Cambrian after which "the mind evolved in response to other minds" (p. 63). This transition should be understood as the evolution of representing other minds' knowledge. An important question for both predator and prey becomes: Have I been seen? The existence of eyes appears to function as a shorthand for many animals to make just this inference - when eyes meet, one infers knowledge of ones' location to the subject at the other end of this exchange. Burrowing, ink release, and flight are useful attempts to break this link. Many predators avoid the eye contact of their prey at all cost. Knowledge and ignorance of one's surroundings can make all the difference to survival. The evolution of eye-spots on butterflies is one spectacular invention to make potential predators think that they are seen, thus avoiding conflict. Behaviourists may appeal to simpler explanations, but in this case, knowledge attribution may not be such a complex affair. To see others in one's environment as subjects is bound to give one an edge over others in an ecology of interaction. But to treat others as subjects entails the attribution of knowledge.

The picture I have offered here is a speculative one - one that ties the explosion of diversity during the Cambrian to the recognition of other minds' knowledge. Nevertheless, it offers additional support to the main conclusion in Phillips et al. Focusing on human representations of other minds might have biased us against a much more basic approach to other minds research. The attribution of knowledge to other minds may be an evolutionarily much more ancient trait than the attribution of belief.

\section{References}

Bengtson, S. (2002). Origins and early evolution of predation. Paleontological Society Papers 8, 289-318. doi:10.1017/S1089332600001133.

Dennett, D.C. 1987. The Intentional Stance, Cambridge, MA: MIT Press. 
Ginsburg, S. \& Jablonka, E. (2019). The Evolution of the Sensitive Soul: Learning and the Origins of Consciousness.

MIT Press, London.

Godfrey-Smith, P. (2017). The subject as cause and effect of evolution. Interface focus, 7(5), 20170022. https://doi.org/10.1098/rsfs.2017.0022

Godfrey-Smith, P. (2016). Animal evolution and the origins of experience. In D. Livingstone Smith (Ed.),How Biology Shapes Philosophy: New Foundations for Naturalism, pp. 51-71.

Maloof, A. C.; Porter, S. M.; Moore, J. L.; Dudas, F. O.; Bowring, S. A.; Higgins, J. A.; Fike, D. A.; Eddy, M. P. (2010). "The earliest Cambrian record of animals and ocean geochemical change". Geological Society of America Bulletin. 122 (11-12): 1731-1774.

Marticorena, D. C. W., Ruiz, A. M., Mukerji, C., Goddu, A., \& Santos, L. R. (2011). Monkeys represent others' knowledge but not their beliefs. Developmental Science, 14(6), 1406-1416. doi:10.1111/j.1467-7687.2011.01085.x

Martin, A., \& Santos, L. R. (2014). The origins of belief representation: Monkeys fail to automatically represent others' beliefs. Cognition, 130(3), 300-308.

Martin, A., \& Santos, L. R. (2016). What cognitive representations support primate theory of mind?. Trends in Cognitive Sciences, 20(5), 375-382.

Phillips, J., Buckwalter, W., Cushman, F., Friedman, O., Martin, A., Turri, J., . . Knobe, J. (2020). Knowledge before Belief. Behavioral and Brain Sciences, 1-37. doi:10.1017/S0140525X20000618

Veit, W. \& Huebner, B. (2020). Drawing the boundaries of animal sentience - Animal Sentience 29(13). https://animalstudiesrepository.org/animsent/vol5/iss29/13/.

Veit, W., Dewhurst, J., Dołega, K., Jones, M., Stanley, S., Frankish, K. \& Dennett, D.C. (2020). The Rationale of Rationalization - Behavioral and Brain Sciences 43, e53.

https://doi.org/10.31234/osf.io/b5xkt

Wray, G. A. (2015). Molecular clocks and the early evolution of metazoan nervous systems. Philosophical Transactions of the Royal Society B 370, 20150046. doi:10.1098/ rstb.2015.0046. 